\title{
Applicability of Floating Foundation for Offshore Wind Turbine in East China Sea
}

\author{
Ke Fan \\ Shanghai Investigation Design \& Research Institute, Shanghai China \\ 200434 \\ fanke200890@126.com
}

\begin{abstract}
Keywords: the East China Sea; floating foundation; structural selecting
Abstract. Combining with the environmental load characteristics in the East China Sea and the existing floating foundation types, by analyzing the applicability of the floating foundation in the target area, it is considered that TLP and Semi-submersible foundation are suitable for the floating wind turbine foundation at the present stage.
\end{abstract}

\section{Introduction}

Offshore wind energy is an abundant, less restricted resource which is the focus of research and application in recent years. As of 2016, the cumulative installed capacity of offshore wind power in China reached 1630MW, ranking third in the world. Roughly estimated, Since 2016, 6 offshore wind projects, totaling 1582MW, were approved and 8 more projects, totaling 1920MW, have been in construction[1]. Offshore wind foundations include the high pile platform foundation, the high pile low platform foundation, the monopile foundation and the jacket foundation, all of which belong to the fixed foundation. fixed foundations are relatively economical, and more suitable for shallow and medium depth sea area. Due to the restriction of coastal resources, offshore wind power industry has a trend of development to the deep sea gradually. For deeper and farther waters, using fixed offshore wind turbine foundation leads to a substantial increase of the project cost, and the design and construction difficulty.. Meanwhile, the installation cost of offshore floating wind turbine foundation and mooring system is relatively low, and has broader market prospect. Floating wind turbine can be constructed in open sea areas to obtain abundant wind energy, avoiding visual and noise pollution. China has the most deep-water wind energy resources. For the South China Sea, Taiwan and other areas in China, due to the deep water depth nearshore, floating foundation is needed to the offshore wind farm construction. Besides, for the development of isolated islands such as the East China Sea and the South China Sea, using floating offshore wind turbine foundation is the most predominant renewable energy development measure.

\section{Introduction to offshore wind turbine floating foundations}

Offshore wind turbine foundations mainly include Spar foundation, Semi-submersible foundation, TLP foundation and Barge foundation, all of which are evolved from offshore oil production platforms. Spar foundation works by lowing the center of gravity until it is lower than the center of the buoyancy to obtain static stability, and it is anchored by catenary or tension line. Spar foundation is suitable for the sea area with deeper water depth and wider available seabed area (Fig. 1). Semi-submersible foundation obtains static stability by using a few small waterplane area which is far away from each other. Its size is large and the sea area covers a wide area (Fig. 2). TLP foundation obtains static stability by the mooring tension which is bigger than the buoyancy force provided by the floating body. The structure is stable, the mooring system requirements are strict, and needs less seabed area than other foundations (Fig. 3). Barge foundation is evolved from FPSO oil platform, and the barge provides buoyancy for the wind turbine.( Fig. 4). 

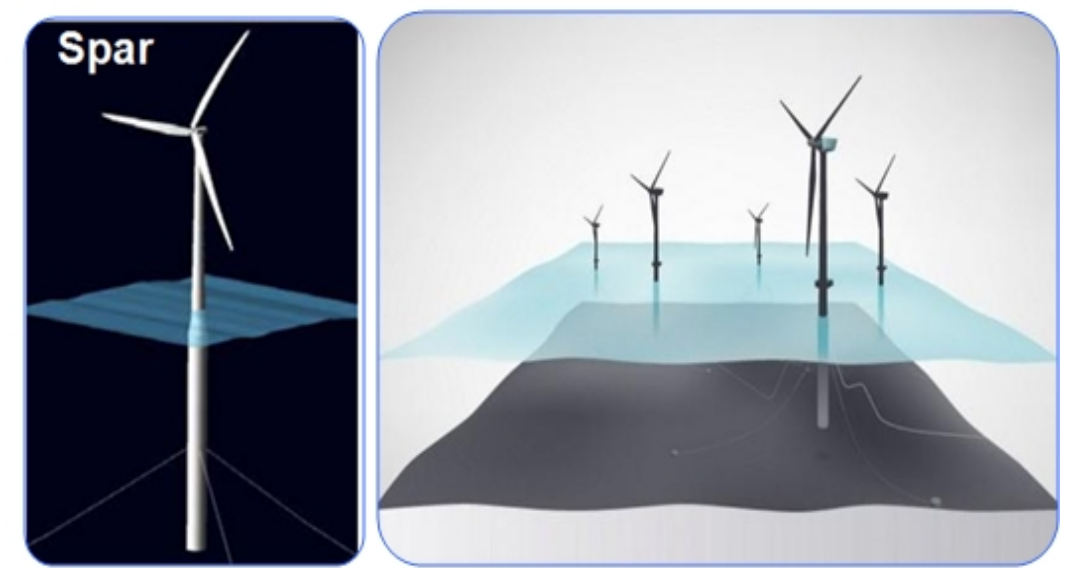

Fig. 1 Spar wind turbine foundation
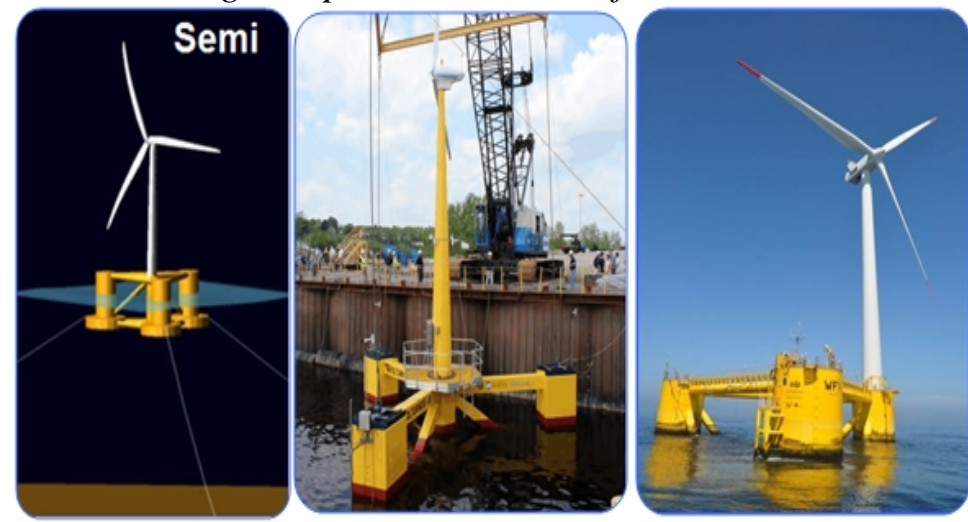

Fig. 2 Semi- submersible wind turbine foundation
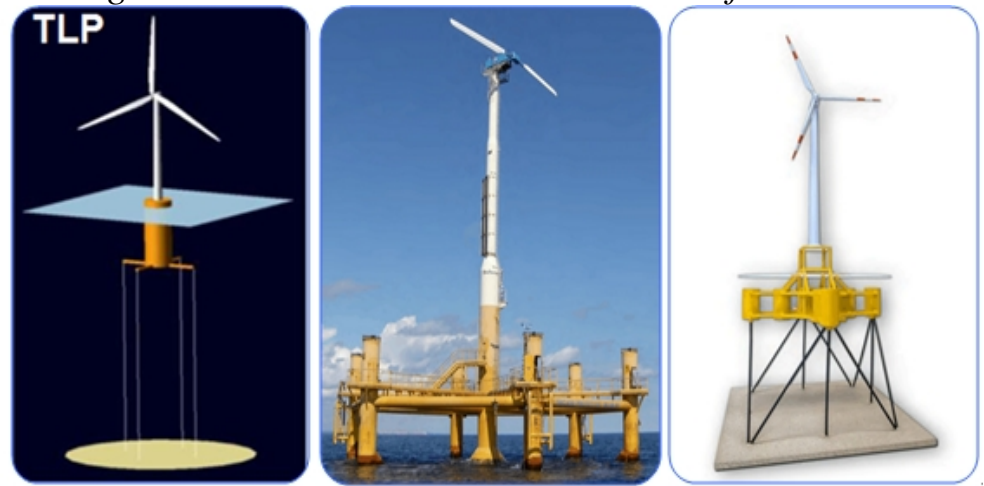

Fig. 3 TLP wind turbine foundation
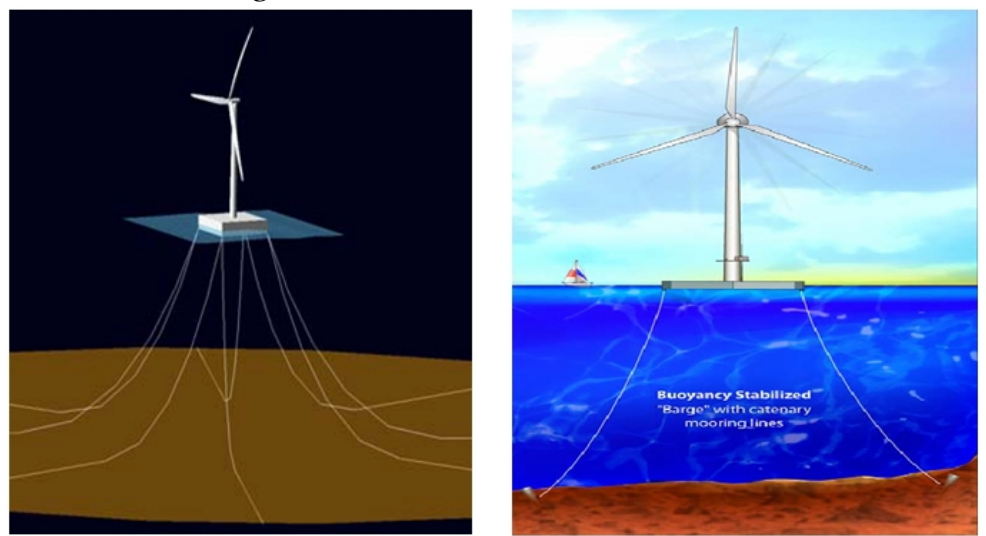

Fig. 4 Barge wind turbine foundation 


\section{Environmental conditions of the East China Sea}

The East China Sea is in the East Asian monsoon region, and is affected by winter and summer monsoons. Wind energy resources are abundant And worthwhile for development and utilization, especially in offshore areas, which is broader and with less obstructions.. The research shows that the wind resource condition is superior in the East China Sea. Taking Shanghai Seas for example, the average wind speed is close to 8 meter per second $(\mathrm{m} / \mathrm{s})$ near the coastline of Nanhui[2]. Tropical cyclone, being the most serious disastrous weather for the wind farm, is worth of serious consideration in the construction of wind farms.. The path of super typhoon storm should be evaded in the wind farm site selection.

Continental shelf of the East Sea is beneath the East China Sea, and it is one of the widest continental shelves in the world. The East China Sea is wide in north and narrow in south, with an average depth of 72 meters. Wave is strongest in winter, followed by autumn and spring, and summer is the weakest.

The Annual mean effective wave height in coastal area of East China Sea is within the range of 1.5 to $2.4 \mathrm{~m}$, and increases gradually from north to south. Due to the narrow pipe effect, Taiwan Strait Region has the strongest wave in the East China Sea and the average wave height is about $2.4 \mathrm{~m} \mathrm{[3].}$ The peak period of the East China Sea fluctuates from 6 to $9 \mathrm{~s}$, and increases from north to south. The East China Sea is mostly influenced by semidiurnal tide. According to Da Ji Shan Tidal Station data, the tidal range between extreme high tide level and extreme low tide level is about $7 \mathrm{~m}$. The regional ocean currents, together with the currents of the Bohai Sea and the Yellow Sea, are mainly composed of the two streams, the Kuroshio current and the coastal current, which have the characteristics of cyclonic circulation. Generally, the velocity of ocean currents is lower than wave, resulting in less influence on the offshore wind power design.

Since Quaternary, tectonic movements have been dominated by differential uplift and movement in East China Sea, and huge unconsolidated Quaternary sediments have been deposited, leading to better regional structural stability.

\section{Application of floating wind turbine foundation in China}

The worldwide research on floating offshore wind power has more than 20 years of history, and StatoilHydro built the world's first floating offshore wind turbine in 2009. Up to now, floating offshore wind turbines have been built in Europe, North America and Japan. While, China spends only ten years on that research, which focuses mainly on academic perspective. In recent years, With the further development of offshore wind in China, it is of great importance and urgency for China to participate in the construction of floating offshore wind power.

Offshore wind turbine foundation has a series of engineering characteristics, including large power foundation, towering structure foundation, marine structure foundation, which need to combine the environmental load structure, motion response, structure strength, fatigue and construction conditions. As the obvious characteristics of motion response and complex coupling effect being the main reasons differing floating foundation from fixed foundation, these characteristics should be considered and calculated with top priority. For floating offshore wind turbine foundation, the main influence factors of motion response are wave load and wind load. The wave load has the more severe influence on motion response at the water plane, especially for the structure without horizontal load constraint. Wind load gives a big influence on the towering structure, and makes a more stringent requirement for the foundation strength.

Spar foundation, due to its deep draft, bears weaker vertical excitation force and consequently exhibits lighter motion response in heave direction. Spar foundation has a better heave performance than the semi submersible foundation, but because of its small water plane area, it has big roll motion and pitch motion. The gravity center of Spar foundation is beneath the buoyant center, so the working depth is usually larger than $100 \mathrm{~m}$. For the East China Sea, considering the transmission distance of power system and water depth for the foundation, there are not many sea areas suitable for Spar. 
Furthermore, there are some important cables laying under water in the East China Sea, which may cause some certain restrictions on the mooring arrangement.

Semi-submersible foundation is currently the most mature technology of the floating wind power foundation. The wind turbine foundation is constructed on shore, and then towed to the designated place with pre-installed mooring system. It has a shallow draft and several outstanding characteristics, including stability in transportation and installation, flexibility, reliability and frugality. The foundation is usually fixed by a certain number of catenary to the bottom of the sea. It needs a large area of seabed, which is suitable for the sea area with less barrier. The structure of a good adaptability to water depth is beneficial to the transmission of power system. However, comparing to Spar and TLP, its larger motion response raises the requirements for wind turbines performance. Overall, Semi-submersible foundation is suitable for the East China Sea.

The tension mooring system of TLP foundation is complex, and the tension tendon needs maintenance. But those imperfections are well compensated by the its exceptional properties on depth adaptability, stability, and suspension and swing motion. Furthermore, it requires less on wind turbine performance and usable sea area. It is a very suitable foundation type for the East China Sea.

Barge foundation has no engineering precedents in the world at present, and its economic type needs further research, so it is not in consideration at the present stage.

\section{Conclusions}

According to the environmental load characteristics in the East China Sea and the existing floating characteristics of foundation, it is considered that the TLP foundation and Semi-submersible foundation are suitable for the selection of the floating wind turbine foundation in the East China Sea. A glorious future is depicted by the proliferation of floating wind turbine industry into the abysmal sea area.

\section{Literature References}

References are cited in the text just by square brackets [1]. (If square brackets are not available, slashes may be used instead, e.g. /2/.) Two or more references at a time may be put in one set of brackets $[3,4]$. The references are to be numbered in the order in which they are cited in the text and are to be listed at the end of the contribution under a heading References, see our example below.

\section{Acknowledgements}

This work was funded supported by the Natural Science Foundation of Shanghai Municipality (16DZ1203502).

\section{References}

[1] Information on http://www.bjx.com.cn/

[2] Information on https://baike.baidu.com/

[3] SU J. L. Hydrology in the China Seas[M]. Beijing:OceanPress,2005. 